\title{
EXPERIMENTAL INFECTION OF TWO SPECIES OF WRASSE WITH THE DIGENEAN PROCTOECES SUBTENUIS
}

\author{
By R. F. H. Freeman \\ Department of Zoology, Queen Mary College, University of London
}

(Text-figs. I and 2)

\begin{abstract}
Adult specimens of the digenean Proctoeces subtenuis (Linton, 1907) Hanson, I950 have recently been recorded from the kidney of the lamellibranch Scrobicularia plana (da Costa) from Chalkwell in the Thames estuary (Freeman \& Llewellyn, 1958), and also, under the name of Proctoeces maculatus, from Mytilus edulis L. from the Woods Hole-New York region by Stunkard \& Uzmann (1959), and by Uzmann (1953). P. subtenuis has usually been recorded from the hind-gut of labrid and sparid fishes in tropical and subtropical seas, and Freeman \& Llewellyn suggested that the occurrence of adult forms of the parasite in an invertebrate host was probably abnormal, and that the more normal life cycle includes a vertebrate as the definitive host. In Britain $P$. subtenuis has never been recorded from a fish, and so it has not been possible to make a direct comparison of specimens from an invertebrate with specimens from a vertebrate. It was therefore decided to attempt to infect suitable British fishes with specimens of $P$. subtenuis obtained from $S$. plana, and to compare any surviving parasites from these fishes with others collected directly from the mollusc.
\end{abstract}

\section{MATERIALS AND METHODS}

The fishes used in the experiments were the only two labrids available in sufficiently large numbers in the Plymouth area, the two wrasse species Ctenolabrus rupestris (L.) and Crenilabrus melops (L.). A total of 35 wrasse was used, the fishes being divided into two groups. Those of the first group of I8 (Io C. rupestris and 8 C. melops) were killed and their alimentary canals examined. Many of them were found to contain adult digeneans belonging to the family Allocreadiidae, as had been recorded previously by Nicoll (I9IO, I9I4), and one of them had two unidentified metacercariae encysted in the peritoneal fat, but not one of them contained a single specimen of $P$. subtenuis. It was therefore assumed that the remaining $\mathrm{I} 7$ wrasse $(7 \mathrm{C}$. rupestris and ro $C$. melops) to be used in subsequent experiments were free from naturally occurring $P$. subtenuis. These 17 specimens of wrasse varied in length between IO and $20 \mathrm{~cm}$. The sizes of the fishes in which $P$. subtenuis 
has been found are not given in any of the previous descriptions of the parasite, but Smith (I949) lists Thalassoma lunare (L.) as about $25 \mathrm{~cm}$ long, and figures Sparus bifasciatus (Forskål) as about $20 \mathrm{~cm}$ long. The wrasse were kept under sea-water circulation in the laboratory, and were trained to feed on pieces of scallop and ragworm (previously examined to ensure that they were free from infective stages of digeneans) in such a manner that the pieces of food offered to them could be seen to be swallowed by the fishes. For convenience in carrying out the experiments the wrasse were isolated in groups of three or four in separate tanks.

Specimens of Scrobicularia plana were collected at Chalkwell and also maintained in circulating sea water at Plymouth. Over 700 specimens of $S$. plana were used in the experiments, and the kidney of every one of them was found to contain living specimens of Proctoeces subtenuis. The mean number of parasites per host in a random sample of $S$. plana was found to be between 4 and 5, and since this value was consistent with that found in the earlier investigation, it was used as a basis for subsequent calculations.

Infected kidneys were fed to the isolated groups of wrasse. It was often not possible to count the exact number of kidneys taken by an individual fish, but since only 3 or 4 fishes were infected at a time, care could be taken to ensure that the food was fairly evenly distributed. This feeding with parasitized kidney was continued over periods varying from 2 to 7 days according to the degree of infection required to be introduced, and records were kept of the estimated number of kidneys fed to each fish. Subsequently feeding with uninfected scallop and ragworm was resumed.

The experimental fishes were decapitated in turn, at intervals varying between I and 24 days after the cessation of feeding with parasitized food, and the guts searched for parasites, note being taken of the number and location of any parasites recovered.

During the early stages of the experiments it became apparent that there was a characteristic decrease in the level of infection of the fishes after about 5 or 6 days, and so at the end of such an interval one specimen of Crenilabrus melops was re-exposed to the standard infecting treatment to see whether a high parasite population could be re-established, or whether the fish might have acquired some immunity to $P$. subtenuis.

\section{RESULTS}

Over half of the experimental fishes were found on dissection to contain living specimens of Proctoeces subtenuis. Most of these parasites were found firmly attached to the wall of the short hind-gut, as has been reported for naturally occurring infestations of $P$. subtenuis, though occasional specimens were found attached to the wall of the posterior part of the intestine.

The number of parasites recovered, and the estimated level of infection that 
had been introduced experimentally, together with other relevant information, are summarized in Table I.

The decline of the infection level with time is expressed graphically in Fig. I.

These results show that, in both host species, about $20 \%$ of the estimated

TABLE 1. RESULTS OF INFECTION EXPERIMENTS

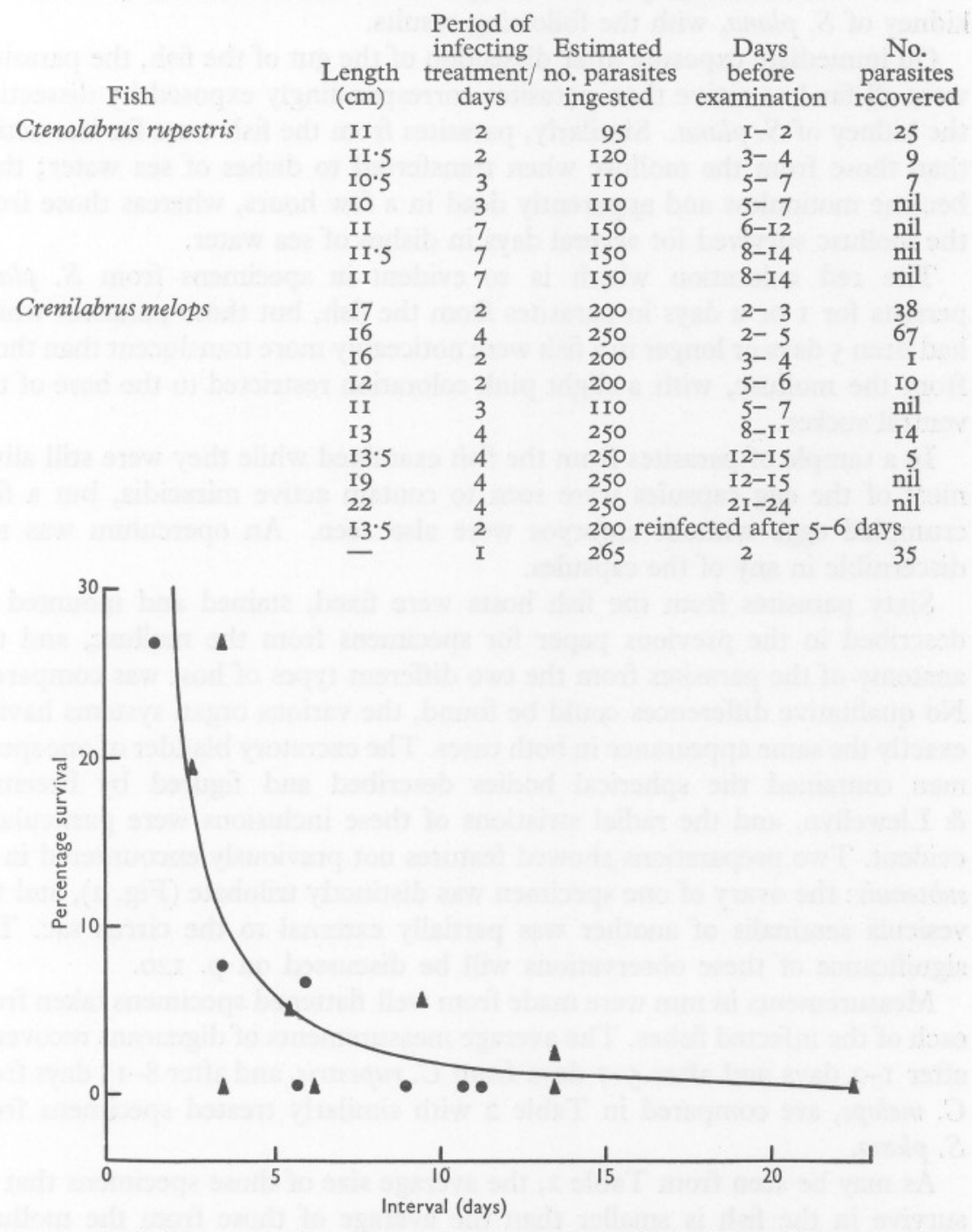

Fig. I. Survival of Proctoeces subtenuis introduced experimentally into'Ctenolabrus rupestris (๑) and Crenilabrus melops $(\boldsymbol{\Delta})$. The interval is that between the introduction of the parasite and subsequent examination of the fish. 
number of experimentally introduced parasites became established for periods of up to 2-3 days, but that thereafter the infection declined to about $5 \%$ after about 5 days. There were no survivors after about 6 days in C. rupestris, but on one occasion 5 parasites, out of about 250 introduced, remained in $C$. melops for about 12-15 days.

The specimens of $P$. subtenuis recovered after they had spent some time in the fish host were compared with specimens collected directly from the kidney of $S$. plana, with the following results.

On immediate exposure after dissection of the gut of the fish, the parasites were all far less active than parasites correspondingly exposed by dissecting the kidney of $S$. plana. Similarly, parasites from the fish were far less active than those from the mollusc when transferred to dishes of sea water; they became motionless and apparently dead in a few hours, whereas those from the mollusc survived for several days in dishes of sea water.

The red coloration which is so evident in specimens from $S$. plana persists for I or 2 days in parasites from the fish, but those parasites which had been 5 days or longer in a fish were noticeably more translucent than those from the mollusc, with a slight pink coloration restricted to the base of the ventral sucker.

In a sample of parasites from the fish examined while they were still alive, most of the egg capsules were seen to contain active miracidia, but a few crumpled eggs without embryos were also seen. An operculum was not discernible in any of the capsules.

Sixty parasites from the fish hosts were fixed, stained and mounted as described in the previous paper for specimens from the mollusc, and the anatomy of the parasites from the two different types of host was compared. No qualitative differences could be found, the various organ systems having exactly the same appearance in both cases. The excretory bladder of one specimen contained the spherical bodies described and figured by Freeman \& Llewellyn, and the radial striations of these inclusions were particularly evident. Two preparations showed features not previously encountered in $P$. subtenuis: the ovary of one specimen was distinctly trilobate (Fig. 2), and the vesicula seminalis of another was partially external to the cirrus sac. The significance of these observations will be discussed on p. I20.

Measurements in mm were made from well flattened specimens taken from each of the infected fishes. The average measurements of digeneans recovered after I-2 days and after 5-7 days from $C$. rupestris, and after 8-15 days from C. melops, are compared in Table 2 with similarly treated specimens from S. plana.

As may be seen from Table 2, the average size of those specimens that do survive in the fish is smaller than the average of those from the mollusc. Those recovered after 5-7 days in Ctenolabrus rupestris were particularly small, and most notable were the small dimensions of the cirrus sac and 
gonads. The ratios of the sizes of these reproductive organs to body length are given in Table 3 for specimens recovered after I-2 days, and after 5-7 days, in C. rupestris.

This comparison shows that the cirrus sac and gonads are relatively, as well as absolutely, smaller in those digeneans that survive longest in this wrasse species. It should, however, be noted that, in all the specimens measured, egg capsules were present and were of normal size.

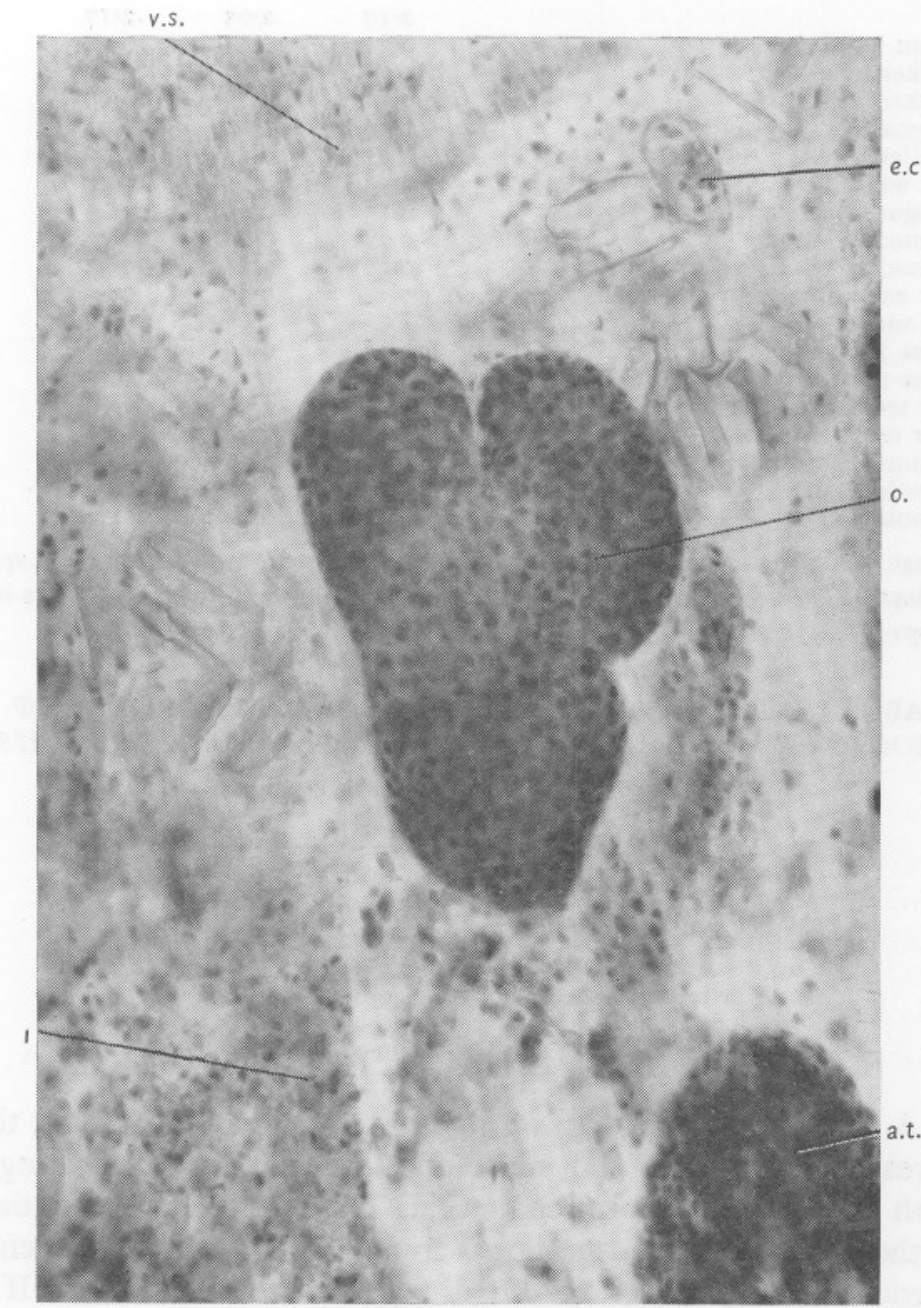

Fig. 2. Proctoeces subtenuis. Photomicrograph of part of whole specimen showing the trilobate ovary and adjacent structures. a.t., anterior testis; e.c., egg capsules; $i$, intestine; $o$, ovary; v.s., ventral sucker. 
The only physiological comparison it seemed feasible to consider was to investigate in specimens from the fish host a possible deficiency in the complement of the quinone-tanning system as was found in specimens from the mollusc (Freeman \& Llewellyn, 1958, pp. 446-7). Some of the appropriate histochemical tests were therefore repeated on parasites recovered from the

TABLE 2. MEASUREMENTS OF PROCTOECES SUBTENUIS

$\begin{array}{llllc} & \text { (millimetres) } & & \\ \text { Length } & A & B & C & D \\ \text { Maximum width } & 2.17 & 2.05 & 2.17 & 2.92 \\ \text { Oral sucker length } & 0.81 & 0.54 & 0.72 & 0.96 \\ \text { Oral sucker width } & 0.19 & 0.17 & 0.17 & 0.20 \\ \text { Prepharynx length } & 0.18 & 0.18 & 0.18 & 0.21 \\ \text { Pharynx length } & 0.02 & 0.014 & 0.01 & 0.03 \\ \text { Pharynx width } & 0.15 & 0.13 & 0.10 & 0.15 \\ \text { Oesophagus length } & 0.13 & 0.11 & 0.14 & 0.15 \\ \text { Ventral sucker length } & 0.13 & 0.09 & 0.09 & 0.22 \\ \text { Ventral sucker width } & 0.28 & 0.28 & 0.26 & 0.34 \\ \text { Anterior end of body to anterior border of } & 0.36 & 0.35 & 0.35 & 0.39 \\ \text { ventral sucker } & 0.54 & 0.55 & 0.49 & 0.90 \\ \text { Cirrus sac length } & 0.38 & 0.33 & 0.34 & 0.54 \\ \text { Cirrus sac maximum width } & 0.13 & 0.11 & 0.12 & 0.13 \\ \text { Anterior testis diameter } & 0.19 & 0.16 & 0.17 & 0.19 \\ \text { Posterior testis diameter } & 0.20 & 0.16 & 0.22 & 0.21 \\ \text { Germarium diameter } & 0.17 & 0.12 & 0.17 & 0.16 \\ \text { Egg capsule length } & 0.044 & 0.044 & 0.043 & 0.042 \\ \text { Egg capsule width } & 0.026 & 0.024 & 0.024 & 0.024\end{array}$

$A$, Average of 6 specimens after $\mathrm{I}-2$ days in Ctenolabrus rupestris; $B$, Average of 4 specimens after 5-7 days in Ctenolabrus rupestris; $C$, Average of 5 specimens after 8-15 days in Crenilabrus melops; $D$, Average of io specimens from Scrobicularia plana.

TABLE 3. RELATIVE SIZES OF REPRODUCTIVE ORGANS OF PROCTOECES SUBTENUIS FROM CTENOLABRUS RUPESTRIS

Ratio of reproductive organ size to body length

$\begin{array}{lcc}\begin{array}{c}\text { Reproductive organ } \\ \text { dimension }\end{array} & \begin{array}{c}\text { After } \\ \text { I-2 days }\end{array} & \begin{array}{c}\text { After } \\ 5-7 \text { days }\end{array} \\ \text { Cirrus sac length } & 0.175 & 0.16 \mathrm{I} \\ \text { Cirrus sac maximum width } & 0.060 & 0.053 \\ \text { Anterior testis diameter } & 0.087 & 0.078 \\ \text { Posterior testis diameter } & 0.092 & 0.078 \\ \text { Germarium diameter } & 0.080 & 0.055\end{array}$

wrasse. A weak reaction was given to ammonium molybdate and the diazonium reagent Fast Red B, but no reaction was given on incubating specimens with catechol or protocatechuic acid. These results are essentially the same as those obtained with specimens from $S$. plana, and the absence of a phenol-oxidase acting on certain dihydroxyphenols is confirmed. If this is regarded as a deficiency in the egg-making apparatus, as suggested by Stunkard \& Uzmann (I959), it evidently persists in the fish host. 


\section{DISCUSSION}

Since every one of the specimens in the random sample of over half of the experimental hosts was shown to be free from $P$. subtenuis before the infecting treatment, and since in over half of those that were given the infecting treatment parasites were recovered subsequently, it was concluded that the parasites collected from the fishes were in fact survivors from those introduced experimentally. It is evident that if Scrobicularia plana infected with $P$. subtenuis were to be eaten by a labrid under natural conditions in the Thames estuary, then some of the parasites could probably survive for periods of 5-6 days, and perhaps even up to 2 weeks. Moreover, the site of infection would very probably be the hind-gut of the fish, i.e. the same as that in naturally occurring infections by $P$. subtenuis in other parts of the world.

The period of survival of the parasite in fish hosts under experimental conditions was found to be limited (Fig. I). If it is true also of natural infections of fish hosts that the parasite survives for only a short time, then the discovery of $P$. subtenuis in a fish host might be expected to be comparatively rare, depending on the examination of a fish which had become infected not longer than a few days previously. This is largely consistent with the information available in the literature. Only two authors (Manter, I947; Manter \& Pritchard, 1962) have listed the total number of fishes in the sample examined, and they found only 6 specimens of $P$. subtenuis in 4 of 29 hosts examined at Tortugas, and 4 specimens in 2 of 49 hosts from Hawaii. Altogether P. subtenuis has been recorded from fish hosts on 12 occasions (see Table 4 in Freeman \& Llewellyn, I958), and on 8 of these only one or two specimens were found.

That the progressive decrease in numbers of introduced digeneans which survive is probably not due to the acquisition of an immunity by the host is suggested by the success of a second infection after 5-6 days.

The measurements summarized in Table 2 show that the average size of those parasites which did survive in the fish was smaller than that of parasites taken directly from the kidney of the mollusc. Altogether about 3500 digeneans were ingested by the wrasses, and this number must surely have included the size range for which measurements were given by Freeman \& Llewellyn, yet none of the larger specimens was recovered. The evidence from Table 3 suggests that the specimens which survive longest in the fish are not only smaller in total body size, but have relatively smaller reproductive organs. A survey of the sizes of $P$. subtenuis recorded from natural infections of labrid and sparid fishes reveals an interesting fact never previously noted. Altogether 32 specimens of the digenean have been recorded from these families of fish, 2I from 4 species of Sparidae and II from 5 species of Labridae, and 7 of the specimens from labrids have been described as small 
or immature (Odhner, I9II; Linton, 1907), whereas no such comment has been made on any specimens from a sparid. The only record of $P$. subtenuis from a fish of another family is that of Manter (1954), who found 3 mature and 2 immature specimens in Latridopsis ciliaris (Forster) (family Latridae). One conclusion that may be suggested from these observations is that fishes of the family Sparidae may be more appropriate vertebrate hosts of adult $P$. subtenuis than are labrids. However, such a conclusion can only be provisional until much more information is available on the relations of host size to size of parasite (sparids are generally larger than labrids), the conditions under which parasites attain reproductive maturity, and the normal life cycle of P. subtenuis.

The apparent total lack of any structural distinguishing features between specimens of $P$. subtenuis taken directly from a mollusc and those collected after they had spent some time in a vertebrate host gives further support to the hypothesis advanced by Freeman \& Llewellyn that in the life cycle of this digenean there is no need for a vertebrate definitive host. Since in the Thames estuary and in the Woods Hole-New York region $P$. subtenuis apparently does not employ a vertebrate host, and since elsewhere it does, then obviously the inclusion of a vertebrate host in the life cycle is facultative and not obligatory.

The occurrence of a trilobed germarium in one specimen, and of a vesicula seminalis partially external to the cirrus sac in another, are evidently further examples of the intra-specific variation to which attention was drawn in the earlier paper. These variations are of particular interest since the trilobed nature of the germarium was one of the principal distinguishing features of a new species, $P$. major Yamaguti, 1934, and the vesicula seminalis partially external to the cirrus sac was the only specific feature of $P$. insolitus (Nicoll, I9I5) Dollfus, 1952 (syn: Xenopera insolita1). These two species must, therefore, now be considered synonymous with $P$. subtenuis.

The recent accounts by Uzmann (1953) and Stunkard \& Uzmann (1959) of the life cycle of a parasite which they recognize as identical with $P$. subtenuis, but which they prefer to name P. maculatus, in Long Island Sound, and at Woods Hole, Mass., have added considerably to our knowledge of this digenean. Manter \& Pritchard (1962) also prefer to regard P. subtenuis as synonymous with $P$. maculatus, and the whole question of the taxonomy of Proctoeces evidently requires re-examination, particularly in view of the recognition by Caballero (1959) of a family Proctoecidae. Uzmann described a microcercous cercaria developing in sporocysts in Mytilus edulis from localities on both the Long Island and Connecticut shores of the Sound, and named it Cercaria milfordensis. He suggested that it might be the larval stage of Proctoeces on the evidence of finding several specimens of unencysted progenetic larvae referable to this genus in the visceral mass of three mussels

${ }^{1}$ In Freeman \& Llewellyn (1958) Xenopera was misspelt Xenopora. 
bearing $C$. milfordensis infections, and the favourable morphological comparison of these forms. These observations were extended by Stunkard \& Uzmann at Woods Hole, where developmental stages from sporocysts to adults were found in M. edulis. Their work demonstrates that the life cycle of P. subtenuis in American waters can be restricted to invertebrate hosts. In the Thames estuary this restriction is almost certainly due to the introduction of the digenean from some other part of the world, probably tropical or subtropical, and the absence of a suitable fish host, or the inability of any potential host to eat Scrobicularia plana, and it would be interesting to know whether such considerations also apply in the coastal waters between Woods Hole and New York. In these American waters the life cycle of the parasite, from sporocyst formation through cercarial production to mature adult, is accomplished in one species of invertebrate host. This is almost certainly not so in the Thames estuary, where no pre-metacercarial stages have been found in $S$. plana examined at frequent intervals throughout the year. In the earlier paper with Llewellyn we pointed out (p. 45I) that 'the very heavy infection of Scrobicularia plana at Chalkwell... must have been initiated, and must be maintained, by larval stages developing in an invertebrate host'. These larval stages almost certainly develop in a marine lamellibranch, and it seems very likely that this lamellibranch was accidentally introduced into the Thames estuary in fairly recent times. The form of the cercaria of $P$. subtenuis was, until the work of Stunkard \& Uzmann, problematical, but these authors have now shown that in eastern American waters the cercaria is microcercous and occurs in Mytilus edulis. This latter recognition of the larval type of Proctoeces has great significance for the future determination of the life cycle of $P$. subtenuis in Britain. It shifts the search for the infective stages to a mytilid, of which three species, Mytilus edulis L., Modiolus modiolus (L.), and Musculus marmoratus (Forbes) have been recorded from the Thames estuary (Newell, I954). If any of these indigenous British mytilids should prove to harbour a parasite that is elsewhere unknown in Britain, and has almost certainly recently been introduced from tropical or subtropical regions, it will raise problems just as interesting to the malacologist as to the parasitologist.

All the work reported in this paper was carried out at the Plymouth Laboratory, and I am grateful to the Director and his staff for much kindness, particularly Mr A. C. G. Best for taking the photomicrograph illustrated in Fig. 2, and Mr A. C. Briggs for collecting the fish. I also wish to thank Dr J. Llewellyn of the University of Birmingham for the benefit of much helpful discussion at all stages of the work. 


\section{SUMMARY}

Two species of wrasse, Ctenolabrus rupestris (L.) and Crenilabrus melops (L.) were experimentally infected with the digenean Proctoeces subtenuis (Linton) collected from Scrobicularia plana (da Costa). The fishes were killed I-24 days after infection, and the parasite population of their guts examined. About $20 \%$ of the introduced parasites survived for 2-3 days, but the degree of infection decreased with time, the smallest specimens surviving longest. No significant differences were found between parasites from invertebrate and experimental vertebrate hosts.

P. major Yamaguti, 1934, and P. insolitus (Nicoll, 1915) are declared synonymous with $P$. subtenuis (Linton, 1907).

The bearing of these results on the life cycle of $P$. subtenuis is discussed.

\section{REFERENCES}

Caballero y C, E., 1959. Consideraciones en torno a la familia Xenoperidae Poche, 1925 (Trematoda, Digenea Carus, 1863). Rev. Biol. Trop., Vol. 7, pp. 57-6I.

Dollfus, R. P., 1952. Miscellanea helminthologica maroccana. IV. Affinitiés naturelles de Pseudochetosoma salmonicola $\mathrm{R}$. Ph. Dollfus, I95I (famille Steganodermatidae nov.). Emendation de la superfamille Haploporoidea W. Nicoll, 1935. Arch. Inst. Pasteur Maroc., T. 4, pp. 369-86.

Freeman, R. F. H. \& Llewellyn, J., I958. An adult digenetic trematode from an invertebrate host: Proctoeces subtenuis (Linton) from the lamellibranch Scrobicularia plana (da Costa). F. mar. biol. Ass. U.K., Vol. 37, pp. 435-57.

Hanson, M. L., I950. Some digenetic trematodes of marine fishes of Bermuda. Proc. helminth. Soc. Wash., Vol. 17, pp. 74-89.

Linton, E., 1907. Notes on some parasites of Bermuda fishes. Proc. U.S. nat. Mus., Vol. 33, pp. 85-126.

Manter, H. W., 1947. The digenetic trematodes of marine fishes of Tortugas, Florida. Amer. Midl. Nat., Vol. 38, pp. 257-416.

- 1954. Some digenetic trematodes from fishes of New Zealand. Trans. roy. Soc. N.Z., Vol. 82, pp. 475-568.

Manter, H. W. \& Pritchard, M. H., 1962. Studies on digenetic trematodes of Hawaiian fishes: families Fellodistomatidae, Opistholebetidae and Gyliauchenidae. Trans. Amer. micr. Soc., Vol. 81, pp. I13-23.

Newell, G. E., 1954. The marine fauna of Whitstable. Ann. Mag. nat. Hist., Ser. I2, Vol. 7, pp. 32I-50.

Nicoll, W., I9I0. On the Entozoa of fishes from the Firth of Clyde. Parasitology, Vol. 3, pp. 322-59.

- I9I4. The trematode parasites of fishes from the English Channel. F. mar. biol. Ass. U.K., Vol. I0, pp. 466-505.

- 1915. The trematode parasites of North Queensland. III. Parasites of fishes. Parasitology, Vol. 8, pp. 22-4I.

ODHNER, T., I9II. Zum näturlichen System der digenen Trematoden. III. Steringophoridae n.fam. Zool. Anz., Bd. 38, pp. 97-II7.

Smith, J. L. B., I949. The Sea Fishes of Southern Africa. 550 pp. South Africa: Central News Agency Ltd. 
StUNKaRD, H. W. \& UzManN, J. R., I959. The life cycle of the digenetic trematode, Proctoeces maculatus (Looss, I90I) Odhner, I9II (syn. P. subtenuis (Linton, 1907) Hanson, 1950), and description of Cercaria adranocerca n.sp. Biol. Bull., Woods Hole, Vol. II6, pp. 184-93.

Uzmann, J. R., I953. Cercaria milfordensis nov.sp., a microcercous trematode larva from the marine bivalve, Mytilus edulis L. with special reference to its effect on the host. F. Parasit., Vol. 39, pp. 445-5I.

Yamaguti, S., 1934. Studies on the helminth fauna of Japan. Part 2. Trematodes of fishes. I. Fap. F. Zool., Vol. 5, pp. 249-54I. 